\title{
Lidenskapeleg
} fornuft

\section{frå Volda}

«Eg er ein roleg kar. Eg høver til action.» Anestesilækjar Rune Heggedal var fyrste mottakar av Legeforeningens leiarskapspris. Han har jobba fem år på ambulansehelikopter. Ein dag sto han med ei ni år gamal jente i armane, knust av ein bil. Død. Mora var der. Neste dag feira Rune niårsdagen til eldste dottera si. «Det var surrealistisk. Ikkje til å tole på eit vis. Men det er slik det er, dette livet. Når eg står i dei verste situasjonane seier eg til meg sjølv: «Livet er så ille som det er, og no er det du som er her. Gjer det du må.»

Korleis går du fram når du skal portrettere ein framandkar og kollega, ein fyr du aldri har møtt eller høyrt om, truleg lokal helt på Sunnmøre? Du les det du finn og skaffar deg nokre e-postadresser. Emne: «Kven er Rune Heggedal?» Hovudpersonen skaffa kontaktar ved Volda sjukehus. Bestakk han dei grovt? Frå leiande sjukepleiarar og lækjarar fekk eg innboksen full av skryt og positiv baktaling: «Han er en kapasitet i stressa akuttsituasjoner. Bevarer alltid roen, det betyr mye både for kolleger, pasienter og pårørende. Han er spesielt flink til å undervise - kan kunsten å gjøre det vanskelige lett. Som leder er han alltid engasjert, inspirerende, behandler alle aktører i sykehuset likt. Han er konstruktiv i konflikter, kan kunsten å debattere sak og ikke person. Sterke meninger har han, men kommer sjelden på kant med folk. Han er flink til å delegere, og gleder seg når andre mestrer. Han er en svært etterrettelig person, han står alltid for det han sier, med oppriktighet.»

Og slik haldt det fram. Rune Heggedal er fjellmann og skigåar. Han er den gode far som trener sonen sitt fotballag tre gonger i veka. At han er Liverpool-fan trekk ned, men på andre felt vankar det berre skryt: «Rune er opptatt av helsetjenestens organisering, tilbudet til enkeltpasienten. Han fremstår med tung faglig autoritet, omgivelsene hører på ham. Han snakker godt, det er vanskelig å være uenig. Han er fin å samarbeide med, omgjengelig. Rune er en avgjørende faktor i fagmiljøet vårt, med en arbeidsmåte som er gunstig for å klargjøre veien videre.»

Dei mørke sidene eg fekk tak i, var heller puslete: «Når sant skal sies, kan han også være en rotekopp, kontoret ser ut som et bombenedslag og slett ikke alt rutinearbeid blir prioritert. Renholderen har fått beskjed av Rune om ikke å flytte på noe på kontoret hans når hun vasker. Hennes hjertesukk er at det da faktisk knapt er noe sted hun kan vaske, ikke engang på gulvet...»

Portrettøren skjønar at Rune Heggedal er ein gjev kar. Men korleis få grep på eit slikt stykke mjølkesjokoladereklame blant fjord og fjell? Kva er det som gjer han så grom? Kven er han?

Vi møtes til lunsj ved Lille Lungegårdsvann i Bergen sentrum, over eit bord med kvit duk der Bølgen, eller kanskje Moi, som vanleg har fått gaflar og knivar til å stritte ut i lufta frå toppen av vinglasa. Han ser heilt vanleg ut. Han mosjonerer sikkert passe

\section{«Eg meiner det må vere lækjarar med i leiinga av sjukehus, for å verne om faget og pasientane»}

mykje, et sunn mat, drikk med måte, søv passe lenge med gode draumar. Vanlege klede. Vanleg sunnmørsdialekt. Vanleg smånervøs, trur eg, over å hamne i fokus på denne måten, snakke om seg sjølv, bli intervjua i Tidsskriftet. Han drikk eplesaft, eg tek det same. God kald Gravenstein frå flaske, vestlendingsdrykk. Eg finn fram blokk og penn, lener meg attende, avventande, lèt han skjøne at eg har god tid. Allmennpraktikar- kommunikasjonstriks. Kom med det slik du vil, det er din dag - enn så lenge.

\section{Kva er kompetent sjukehusleiing?}

- Eg vil snakke om leiing og organisering i sjukehusvesenet, det er det viktigaste eg har å seie. Eg kom til Anestesiavdelinga i Volda i 1990, vart spesialist i 1995. Eg har vore leiar i 16 år, både før og etter føretaksreforma. Eg har gode røynsler med den gamle todelte leiinga, den ga rom for lækjaren til å vere fagmann også frå leiarposisjon. No har leiaren eit totalansvar som sluker meir krefter og merksemd, du må meir eller mindre velje vekk faget. Det er synd for sjukehusutviklinga. Det er viktig at dei som skal gje direktøren råd er fagleg oppdaterte. Samstundes har sjukehusa fătt stykkprisfinansiering og ei tenking som i det store og heile er styrt av merkantile prinsipp - new public management. Dei som leier sjukehusa seier at pasienten er i sentrum. Kanskje dei trur det sjølve, det er faktisk mogeleg at dei trur det. Dei talar ofte om kvalitet, om kompetanse. Eg opplever jamt at tomme ord er godt nok. Dei som ikkje har klinisk bakgrunn eller ikkje lenger har jamn pasientkontakt, misser noko av innsikta. De utviklar ei forenkla forståing, og denne forståinga ser dei på som fullgod. Så talar dei med andre i same leiarsjiktet, i same bobleverda, dei støttar kvarandre og ender med å ta avgjersler på sviktande grunnlag, smitta av klisjear frå populær leiingsideologi. Det medisinske innhaldet er ofte farleg tynt. Informasjon og synspunkt sirkulerer att og fram mellom departementet og styra i dei store helseføretaka, i ei lukka verd. Intern kritikk vert lamma av lojalitetskrav. Det dannar seg ei hinne mellom leiinga og dei fagfolka som til dagleg kjenner kompleksi- 


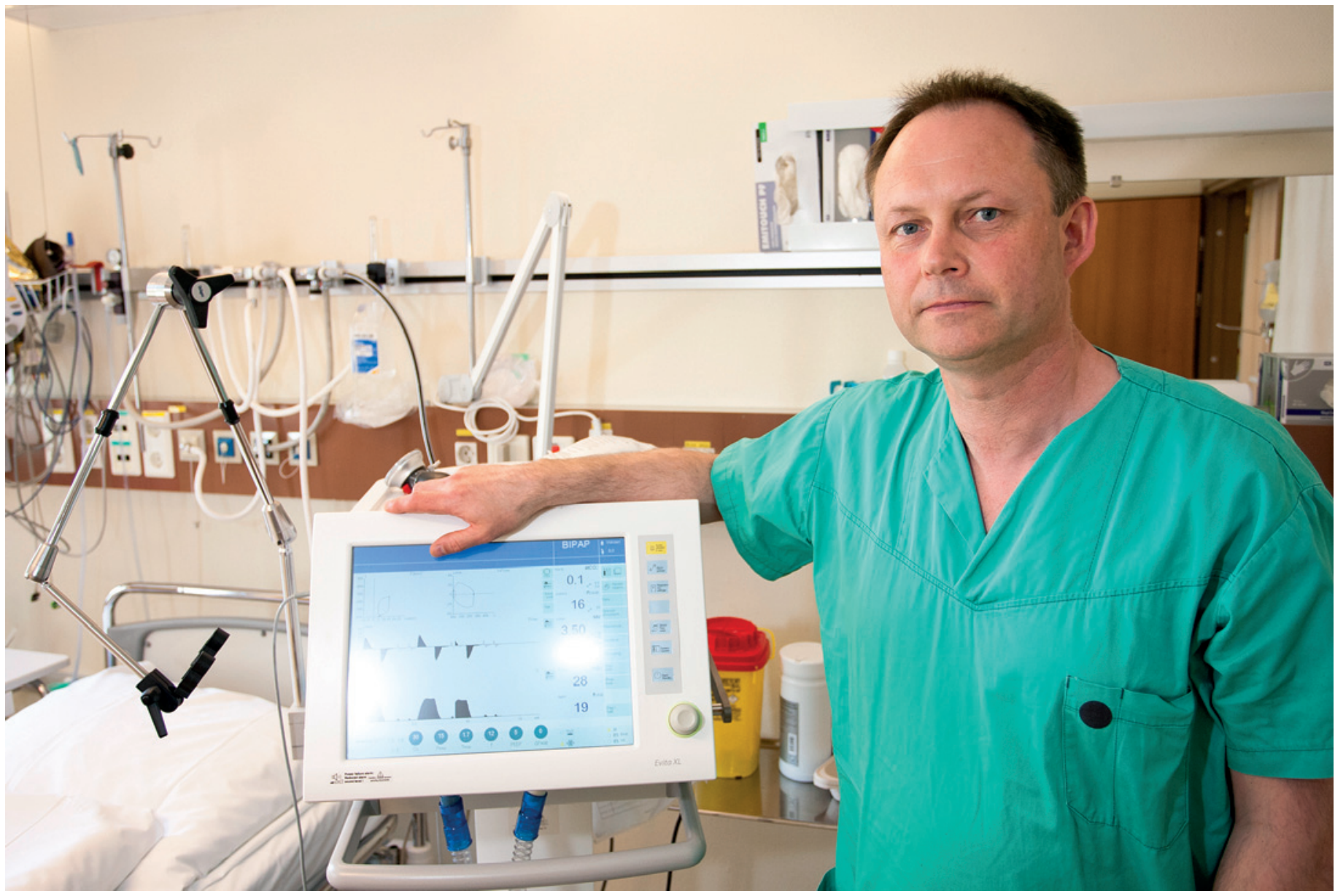

Svein Ove Erkornesvåg/NTB scanpix

\section{Rune Heggedal}

Fødd 23.8. 1960

- Gift med Merete, tre born

- 1986 cand.med. Trondheim, preklinisk praksis i Bergen

- 1995 spesialist i anestesiologi

- 1995 - avdelingsoverlækjar, seinare avdelingssjef ved Akuttavdelinga, Volda sjukehus

- Smertelege i $20 \%$ avtalepraksis sidan 2001

- 2011 Legeforeningens lederskapspris teten, behova, teknologien og lidinga på kroppen. Eg trur den hinna kan bli eit hinder ikkje berre for deling av faktakunnskap og vurderingar, men også for utvikling av eit heilskapleg verdisyn og ein sams ideologi i helsevesenet - med reelt fokus på pasienten.

\section{Audmjuk idealist}

Han talar seg varm, han tenker og leitar etter ord, har knapt tid til å få i seg bacalaosalaten. Han vil at eg skal forstå kva han har erfart, kva han tenker og kva framtid han vil ha. Eg byrjar å sjå kven Rune Heggedal er. Han er ein som trur han kan skape endring, fordi han har klart det før. Eldsjel. Naiv idealist. Ein som stikk hovudet fram fordi nokon må gjere det, for saka. I media har han argumentert for å behalde akuttfunksjonane i lokalsjukehusa, bremse sentraliseringa og mjuke opp meiningslause geografiske grenser mellom helseføretak. Pasientar i Nordfjord har dobbelt så lang veg til «sitt eige» sjukehus i Helse Førde, som til Volda sjukehus i Helse Midt-Norge. Med ei transporttid på 3-4 timar den «rette» vegen kan liv gå tapt, av grunnar som ikkje kan forsvarast. Rune har kritisert sjefar som argumenterer for at god ambulansedekning er like trygt som sjukehus med bemanna akuttmottak. - Dei jamsteller vidaregåande utdanning med medisinsk spesialkunnskap. Det er berre mogeleg om du er komplett uvitande om innhaldet og utfordringane i medisinsk arbeid, seier han. Rune har fått kjeft for å blande seg i ting han ikkje har noko med. Han smiler: - Det var ein som sa at eg brukar legefrakken til å drive politisk agitasjon. Kanskje dei meiner at ein har betre innsikt $i$ vanskelege saker dersom ein er amatør, utan fagleg utdanning, innsikt og røynsle? Eg skulle tru at den gjeld her også den gamle regelen om å lye til erfarne fjellfolk.

Rune Heggedal les politisk og historisk litteratur på fritida. Churchill og Stalin var store politiske figurar, men også dei var nakne under kleda. Med enorm makt endra dei verda, korleis opplevde dei seg sjølve? Før var Rune berre Rune, nå kjenner han at autoriteten frå lækjar- og leiarrollene har krope under huda, han vert møtt med respekt og likar det. Den gode leiaren treng mot til å be om hjelp, heile tida lære meir, forkaste det han trudde, vere liten, uvitande, 
den som lyer. Gjer Rune Heggedal det? Eg trur han høyrer på medarbeidarane og pasientane sine, slik kloke lækjarar gjer. Det er difor dei blir kloke.

\section{Elskar å vere lækjar}

Rune vaks opp i Volda, far dreiv butikk, mor tok hjelpepleiarutdanning etter at Rune var vaksen. Det var ikkje ein intellektuell heim, men det var bøker der.

- Det var slump at eg valde medisin, eg var ambisiøs og ville studere jus eller noko anna som var utfordrande og viste att i det sosiale landskapet. Eg har likt medisinen heilt sidan vi las anatomi og fysiologi i studiet. Eg likar å halde meg oppdatert, eg kjøper jamt lærebøker i intensivmedisin, anestesi, indremedisin, patofysiologi. Og eg les dei. Det gjer meg roleg å kjenne at eg kan det eg driv med, forklarer han.

Han får endeleg slukt litt av salaten, og skyller ned med meir Gravenstein:

- Eg trur eg kan seie det beint ut - eg elskar å vere lækjar! Då eg skjøna at ei klinikksjefstilling ville gjere det uråd å jobbe klinisk, var det lett å seie nei, sjølv om det ville gitt status og makt. Det er lækjaryrket som er livet mitt, identiteten min, det som gjev kvardagen meining. Alt dette med organisering og leiing handlar om å legge til rette for ein einaste ting: at møtet mellom pasient og helsepersonell skal bli bra for pasienten. Dei leiarane eg kjenner, som sjukehusdirektøren vår i Møre og Romsdal, er menneske med integritet. Men dei forstår ikkje alltid det kompliserte og utfordrande kjernestoffet $i$ den verksemda dei styrer kva det krev å vere hjelpar for sjuke menneske, korleis ein finn ut kva folk treng, korleis ein i ein uoversiktleg situasjon skaper gode praktiske løysingar i fellesskap. Du treng taus kunnskap og intuisjon, du må ha prøvd mykje, kjent på å vere usikker og engsteleg, gått i deg sjølv, endra syn, sett korleis folk taklar liv-og-død-situasjonar. Eg meiner det må vere lækjarar med i leiinga av sjukehus, for å verne om faget og pasientane. Du må ikkje berre gjere ting rett, du må gjere dei rette tinga.

- Men kva om ein ikkje har pengar til å gjere dei rette tinga rett? spør eg.

- Det er greitt, men då må dei seie at det er slik det er, og ikkje skjule sanninga bak eit røykteppe av meiningslause argument.

\section{Styring er politikk}

Han tømmer tallerkenen og ser nøgd på meg. Vi blir einige om ein runde med husets mogne ostar. Eg finn fram det vanskelege spørsmålet eg hadde planlagt.

- No har du kritisert opp og ned. Korleis ville du sjølv styrt Helse-Noreg dersom du hadde makt til det? Eg tenker han skal få litt å tygge på ved sida av osten. Men ikkje før har eg fått i meg halve camemberten, så legg han fram ein analyse som sjølv ein fastlege kan nikke til.

- Planane må leggast sentralt. Så må ein overlate gjennomføringa til operativt nivå.

Det som skapar dei verkeleg store problema i dag er at politikarane overlèt dei vanskelegaste politiske sakene til helseføretaka, slik at styresmaktene kan sitje trygt og berre sanksjonere eller avvise det som kjem. Slik sette dei fyr på landsdelen vår med sjukehusstriden mellom Molde og Kristiansund. Slikt er alvor for dei det gjeld, det utvikla

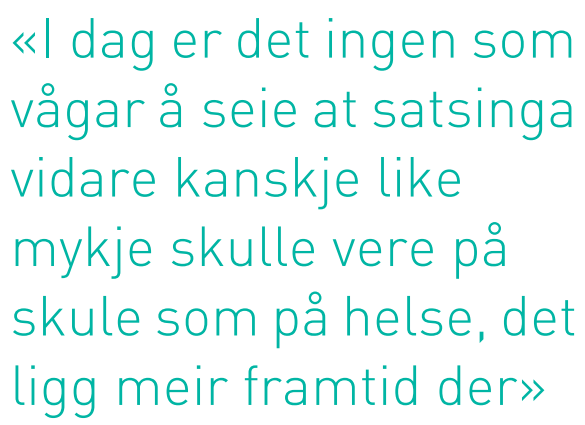

seg ein borgarkrig mellom Romsdal og Nordmøre som eg trur det vil ta generasjonar å komme over. Folk som var vener og partnerar har slutta å tale saman, bloggane er fulle av hatske kommentarar - på grunn av ein lokaliseringsstrid der styresmaktene var for feige til å ta styringa og ansvaret.

Slike vanskelege saker må løysast nasjonalt, med grundig politisk arbeid i gode komitear. Folk vil akseptere eit godt mogna stortingsvedtak. Føretaka er gode på gjennomføring. Vi treng ikkje helseregionane, det er for mange ulemper med dei byråkratiske grensene og nivåa. Rett nok ville eit nasjonalt direktorat fått stor makt, men då kunne vi sett heilskapen for landet vårt der vi no berre ser grenser og rivalar. I dag driv føretaka planlegging og endringar på eiga hand, mest fordi dei ser på endring som positivt i seg sjølve, trur eg. Men endringar må vere målretta, nasjonale og overgripande slik at dei vert oppfatta som rettfer- dige. Då kunne vi kanskje også tole at staten bremsa veksten i helsevesenet. I dag er det ingen som vågar å seie at satsinga vidare kanskje like mykje skulle vere på skule som på helse, det ligg meir framtid der. Eller eit anna døme: No vert det investert 2,2 milliardar i vegar i vårt område. Men på helsesektoren er det snakk om innskrenkingar, sparing og nedbygging av sjukehus i den same regionen. Det er meiningslaust, høgre og venstre hand veit ikkje om kvarandre, slår han fast.

\section{Kjærleik og død}

Han ser på notata han har tatt med, om kva som kan vere viktig å få sagt. Så møter han blikket mitt: - Eg vaks opp med liberale verdiar, privat initiativ og alt det der. Men gjennom livet har eg fått meir og meir sansen for fellesskap, for at vi tek vare på kvarandre og bygger i lag. Eg vil ikkje vere rik viss naboen er fattig. At alle har det rimeleg bra, er ein fantastisk kvalitet ved landet vårt. Vi må ikkje dyrke sjølvgod revirtenking som undergrev solidariteten, understrekar han.

Han ser på arket sitt igjen.

- Og så er det ei heilt anna sak. Eg har tenkt mykje på dette med grenser for behandling. Eg veit at vi er mange som opplever at det er gått for langt. Ingen vågar å seie stopp. Vi skal gje full pakke uansett kor gamle eller sjuke pasientane er, for det er det etisk rette seier dei. Eg er usamd. Som intensivlækjar veit eg at det ikkje er grenser for kva eg vil gjere for å få ein 18-åring gjennom, og at vi alle ser heilt annleis på ein dement 80 -åring. Eg er audmjuk over å ha denne makta. Og eg veit at kritikken sit laust mellom folk som ikkje har opplevd meiningsløysa i den delen av kvardagen vår. Difor trur eg vi treng ein brei debatt om grenser for liv og død, slik at vi kan ha ryggdekning for å bruke vårt eige skjønn, gjere mindre, la folk døy $i$ fred når tida er komen, rundar han av.

Han trur at det nyttar å seie ifrå, Rune Heggedal. Han trur fornufta og dei gode argumenta kan få gjennomslag. Vi skåler i cappuccino før han tek flyet heim til Volda.

Edvin Schei

edvin.schei@isf.uib.no

Tidsskriftet 